\title{
Cultural molding, shielding and shoring at Oilco: The role of culture in the integration of routines
}

\author{
Forthcoming in Organization Science \\ (Special Issue on Routine Dynamics)
}

\author{
Stephanie Bertels \\ Beedie School of Business, Simon Fraser University \\ 500 Granville St., Vancouver, BC V6C 1W6 Canada \\ E-mail: stephanie_bertels@sfu.ca
}

\begin{abstract}
Jennifer Howard-Grenville
Cambridge Judge Business School, University of Cambridge Trumpington Street, Cambridge CB2 1AG United Kingdom E-mail: j.howard-grenville@jbs.cam.ac.uk
\end{abstract}

\begin{abstract}
Simon Pek
Beedie School of Business, Simon Fraser University

500 Granville St., Vancouver, BC V6C 1W6 Canada

E-mail: spek@sfu.ca
\end{abstract}

Keywords: routines; routine integration; organizational culture; cultural molding; cultural shielding; cultural shoring; strategies of action

Acknowledgements: The authors gratefully acknowledge funding from the Social Sciences and Humanities Research Council of Canada. We thank our editor, Martha Feldman, and reviewers for their very thoughtful and constructive engagement with our manuscript. We are also grateful to members of the Beedie Write Club, and seminar participants at HEC (Montreal) and OTREG (Cambridge) for their feedback on earlier versions of this manuscript. We also thank the participants of our study for the generous contribution of their time. 


\title{
Cultural molding, shielding and shoring at Oilco: The role of culture in the integration of routines
}

\begin{abstract}
We explore how organizational culture shapes an organization's integration and enactment of an external routine that is not a cultural fit. Attending to employees' use of culture as a repertoire of strategies of action, we found that the use of familiar cultural strategies of action shaped the routine's artifacts and expectations even before it was performed, a process we call cultural molding. Subsequently, employees drew differently on cultural strategies of action as they performed the routine, generating patterns of workarounds or hindered performances. In response to these patterns, they undertook additional cultural work to either shield their workarounds and protect them from scrutiny, or to shore up hindered performances. We contribute to the routine dynamics literature by highlighting the effortful cultural work involved in integrating coveted routines, furthering our understanding of routines as truces and the embeddedness of routines.
\end{abstract}


Organizations frequently covet others' routines and attempt to enact them as their own, even when such routines are a poor fit. For example, 3M, known for innovating through "serendipitous discovery," nonetheless adopted Six Sigma in an effort to impose discipline and efficiency (Canato et al. 2013, p. 1724). Healthcare organizations adopt business management routines (Lozeau et al. 2002); universities impose compliance routines on labs focused on discovery (Bruns 2009); and for-profit organizations attempt to routinize their commitment to social values (Besharov 2014). Despite being a poor fit, these organizations adopt these routines to acquire new skills (Edmondson et al. 2001), appease stakeholder demands (Bertels and Peloza 2008), or balance competing commitments (Besharov 2014).

Despite the prevalence of this phenomenon and longstanding attention in the literature to the movement of routines from one place to another (Nelson and Winter 1982, Pentland and Feldman 2005, Winter and Szulanski 2002), our understanding of how organizations integrate coveted routines remains limited. Prior work signals that organizations seeking to integrate others' routines face distinct challenges. Work from one perspective, which regards routines as entities and carriers of organizational knowledge, finds that when organizations attempt to adopt others' routines their efforts are complicated by incomplete knowledge of the routine, its tacitness, and managerial overconfidence (Knott 2003, Winter and Szulanski 2002). Work from a second perspective, focusing on routine dynamics, "opens up the internal structure" of routines (Pentland and Feldman 2005, p. 808) and asserts that any routine must yield recognizable patterns of situated actions over time (Feldman and Pentland 2003). The challenges to integration from this perspective stem from the recognition that organizational contexts and people's agency shape routines (Howard-Grenville 2005), so establishing recognizable patterns of action in the face of existing cultures and management styles is difficult and subject to variation across organizations (Edmondson et al. 2001). Indeed, managers and employees are often culturally ill-equipped to take up practices that originate elsewhere, leading to their rejection or alteration (Canato et al. 2013, Lozeau et al. 2002).

In this paper, we explore how a coveted routine is integrated by an organization, and how this process is shaped by organizational members' use of culture. Our approach is consistent with the routine dynamics perspective, which regards routines as effortful accomplishments that have a generative quality (Feldman 
and Pentland 2003, Pentland and Rueter 1994). As well, we adopt a "toolkit" or "repertoire" perspective on culture, which regards culture as an accomplishment that relies on people's skillful use of a set of cultural strategies of action (Swidler 1986, Weber and Dacin 2011). Accordingly, we investigate the puzzle of integrating a routine with poor apparent fit by attending to how actions and patterns that reflect and constitute the routine and the culture shape each other over time.

We focus empirically on "Oilco, "' a major oil producer, whose pioneering operations in the Canadian oil sands wrought its entrepreneurial culture, often described internally as the "Wild West." Oilco employees were lauded for rolling up their sleeves and "just getting oil out of the ground." A regulatory compliance failure at one of its facilities, and the need to cope with growth and public scrutiny led Oilco's leaders to adopt “operational excellence," a widely-used framework for reducing operational risk by standardizing procedures and focusing employees on "consistent, repeatable behaviors." Central to this effort was the integration of a routine for "operational compliance" which focused on employees' regular use of a new comprehensive database of regulatory compliance obligations and associated specific tasks.

Drawing on interviews, observations, and archival records capturing five years of activity, we find that Oilco's effort to integrate the operational compliance routine, despite its poor cultural fit, led to distinct and sustained patterns of action that resembled but departed from the desired, "espoused" (Rerup and Feldman 2011, p. 577) routine. Our analysis shows how these patterns emerged though the processes of cultural molding, shielding, and shoring, which each involved Oilco members' continued use of predominant cultural strategies of action that were misaligned with the espoused routine. Cultural molding influenced how the routine could be performed by shaping its associated artifacts and expectations; in this way, the use of culture shaped the integration of the routine even before it was repeatedly performed. Subsequently, cultural shielding and shoring arose as the routine was repeatedly performed, but through employees' different uses of the same cultural strategies of action. Cultural shielding protected workarounds in the routine, while cultural shoring sought to protect the integrity of the routine itself.

\footnotetext{
${ }^{1}$ Oilco and all personal and worksite names used in this paper are pseudonyms.
} 
Our findings suggest that the integration of a routine that is a poor fit for the adopting organization involves members' skillful manipulation of both their routine performances and their use of cultural strategies of action. Rather than reject the routine outright, or alter it to fit with their culture, employees and managers undertake additional cultural work as they perform the routine and attempt to conceal or compensate for mismatches between their performances and the espoused routine. Further, we find that, consistent with the repertoire perspective on culture (Swidler 1986, 2001), employees use the same cultural strategies of action differently, yielding diverse patterns of action within the same routine.

Our analysis makes several contributions to the literature on routine dynamics. First, we build theory on the processes that unfold when organizations seek to integrate others' routines, extending work that, with very few exceptions (e.g., D’Adderio 2014, Edmondson et al. 2001), has black-boxed situated, longitudinal processes. Rather than finding that employees abandon their familiar strategies of action or avoid performing a routine altogether, we find that they in fact do extra work as they navigate the misfit between their cultural tools at hand and the demands of the routine. In this way, our work also suggests new ways in which routines can be considered effortful accomplishments (Pentland and Rueter 1994) . Second, our work opens up an alternative understanding of routines as truces, moving away from the political and punctuated characterization of this construct and towards a more dynamic cultural conceptualization. Finally, we explore implications of our theorizing for the embeddedness of routines in their organizational contexts, and, specifically, the need to regard routines as mutually constituted with culture through their common grounding in actions.

\section{Theoretical Background}

Routines are "repetitive, recognizable patterns of interdependent actions carried out by multiple actors" (Feldman and Pentland 2003, p. 95). Essential to addressing the puzzle of what happens when organizations covet others' routines and attempt to integrate them, then, is understanding whether and how recognizable patterns of action emerge in the adopting organization. In this section, we review what is known from the routine as entity perspective and from the routine dynamics perspective to ground our inquiry and to surface the challenges to integration that arise, especially when routines are a poor fit for an 
adopting organization. We then introduce the repertoire perspective on culture that portrays culture as dynamic, whereby culture serves as a potential tool, not simply a constraint, that organizational members use as they attempt to integrate routines.

\section{Insights into Integration from a Routine as Entity Perspective}

Scholars who portray routines as entities have considered how organizations adopt others' routines or transfer them between units, expressive of their interest in how organizations learn through routines (Argote and Darr 2000, Szulanski 2000). Organizations that successfully transfer and integrate routines across various locations, as franchises aim to do, reap performance benefits (Knott 2003). This literature identifies several impediments, however, to the effective integration of routines by an adopting organization. First, even when templates exist for a routine, these templates may not be followed, and the adopting organization's culture or structure may be to blame (Szulanski 2000). Management style and skill have also been shown to impede integration. For example, even for seemingly simple routines (building a pizza or operating a printing service) in franchise organizations, employee adherence to routines quickly falls off without managerial reinforcement (Knott 2003). When mergers or acquisitions bring together distinct organizational cultures or management styles, the routine itself might need to change (Szulanski 2000). For example, efforts to convert newly acquired bank affiliates to Banc One's routines sometimes sacrificed "the degree of precision" with which these routines were enacted in order to secure "commitment and cooperation" from a culturally distinct affiliate (ibid, p. 90). While this literature does not go into detail on culture or management styles, it nonetheless concludes that these organizational factors importantly shape how routines are integrated in to a new environment.

A distinct, but related literature probes the transfer of organizational practices, considering, for example, how multinational corporations replicate practices in subsidiaries (Kostova and Roth 2002), and how managerial practices like total quality management diffuse across organizations (David and Strang 2006, Westphal et al. 1997). Findings on the impediments to and enablers of practice transfer are largely consistent with those on routine transfer. For example, high trust between the source and recipient enables practice transfer within multinationals (Kostova and Roth 2002), as does tailoring to local managerial 
styles and cultures (Ansari et al. 2014, Maritan and Brush 2003). Similarly, practice transfer between firms depends both on the degree to which a practice is broadly legitimized (Westphal et al. 1997) and on the internal characteristics of the adopting organization, including its culture (Canato et al. 2013).

Both of these literatures assert that successful integration occurs only when adopting organizations make adjustments to the routine or practice to fit their specific contexts (Ansari et al. 2010, Gondo and Amis 2013, Winter and Szulanski 2002). Ambiguously defined practices, such as quality management or corporate social responsibility, likely demand greater customization (e.g. David and Strang 2006, Wang and Bansal 2012). In fact, lack of willingness to customize a routine can thwart its integration. Managerial overconfidence is one impediment to this and "transfers fail when the people who are trying to stand on the shoulders of giants behave as if they are standing on the ground." (Szulanski in Rerup 2004, p. 148).

While these literatures strongly suggest that routine integration relies on either the serendipitous alignment of an adopting organization's culture with a routine, or the customization of a routine to new cultural and contextual conditions, they stop short of offering an account of how routines are integrated under conditions of poor cultural fit. To develop such an account, a more processual conceptualization is needed, and one that affords a closer look at everyday, situated action. As Szulanski argues:

Most people think in oversimplified ways about transfer, [as if] a good transfer is eventless, costless, and instantaneous. ... [But] a pragmatic conception of transfers, ... acknowledges that ... problems and difficulties are normal, everyday events. (quoted in Rerup 2004, pp. 145-156).

Others echo this call, noting "we understand little about the micro-processes through which actors and actions shape [transfer]" (Friesl and Larty 2013, p. 111). The routine dynamics perspective affords such attention, by focusing on routines as enacted.

\section{Insights into Integration from a Routine Dynamics Perspective}

The routine dynamics perspective asserts that routines are mutually constituted through situated performances - the performative aspect - and abstract patterns of the routine - the ostensive aspect (Feldman and Pentland 2003). Situated performances reproduce or modify the ostensive; conversely, the ostensive operates as a guide and way of accounting for the performative. Another way of conceptualizing these mutual aspects of routines is through the language of actions (the performative) and patterns (the 
ostensives) (Feldman, 2015). This language alerts us even more to the mutual constitution of routines through recognition that a pattern cannot exist independent of action. As well, multiple patterns may arise, perhaps for different actors, as they observe and participate in actions (Turner and Rindova 2012).

The routine dynamics perspective helps frame the puzzle of routine integration in two ways. First, because it foregrounds the mutual constitution of routines through the interplay of actions and patterns, it orients us to attend to integration, or indeed any effort to change or sustain a routine, as a process that unfolds over time. Central to grasping this process is recognizing that actually performing the routine yields enacted patterns, which may depart from those that were espoused (Rerup and Feldman 2011). Peoples' skillful and sometimes intentional actions can lead to distinct patterns taking hold. For example, Edmondson and colleagues (2001) found that surgeons who set out to deliberately alter the status hierarchy and communication practices of a traditional surgical team were able to enact new patterns of collaboration and successfully integrate a new cardiac surgery routine. Conversely, other surgeons who enacted the communication practices prevalent in traditional surgeries reinforced a "captain of the ship" pattern, and were unable to successfully adopt the new routine.

A second insight from the routine dynamics literature is that actions are not undertaken in a vacuum, so the patterns they establish and sustain reflect other aspects of the organizational context (Feldman 2000, Howard-Grenville 2005, Turner and Fern 2012, Zbaracki and Bergen 2010). Several studies show how culture informs the actions people take when performing routines, often resulting in enacted routines that depart pragmatically or temporarily from those espoused, enabling organizational flexibility. For example, localized branch cultures shape how microfinance officers follow or bend the rules in lending routines (Canales 2013). In hospitals, culture can reinforce the value of individual vigilance in carrying out patient care, condoning nurses' departures from espoused nursing routines (Tucker and Edmondson 2003). Managers seeking to impose new routines can be similarly trumped by employee actions that uphold some aspect of an existing culture. For example, in Reynaud's (2005) study, Paris Metro employees asserted an established cultural norm of equality to work around a new routine, thus forestalling its adoption. And Bruns (2009) found that microbiologists in a university laboratory trained 
new postdocs on safety practices in ways that foregrounded their occupational culture, committed to the integrity of experiments, over the organization's commitment to personal safety. Less frequently, culture can prevent departures from an espoused routine, as when employees used their data-driven, disciplined culture to reign in departures from a planning routine (Howard-Grenville 2005).

In sum, culture plays a role in shaping how routines are performed through the specific actions it enables or condones, and it can influence the emergence or suppression of new patterns of action. However, because these studies have tended not to focus on theorizing culture itself, we have limited insight into how culture is also 'in play' as routines are adopted and performed. Work that considers practice integration in relation to organizational culture hints at the dynamism of culture, suggesting how it might be regarded as a vehicle for integrating routines. Studying the introduction of strategic planning and quality management in public hospitals, Lozeau and colleagues (2002) found that existing cultures impeded integration, but that these efforts to integrate practices with low fit could "pave the way for deeper change as people participate in them, and become increasingly socialized to the value they represent" (Lozeau et al. 2002, p. 559). As well, the continued "coerced" exposure of 3M members to Six Sigma practices led them to eventually accept some aspects as culturally compatible, while rejecting others that profoundly challenged core cultural values (Canato et al. 2013). These studies suggest that elements of culture are malleable, an important corrective for exploring the process of routine integration as a series of actions and emergent patterns that are not only delimited by culture but generated through it.

\section{Culture as Dynamic}

Recent work depicts culture as a dynamic, generative system. The "repertoire" or "toolkit" perspective regards cultures as comprised of "relatively small and independent 'bits of meaning"' (Weber and Dacin 2011, p. 289), or cultural resources, as opposed to coherent sets of beliefs that constrain action (Ouchi 1980, Trice and Beyer 1993). Cultural resources include "schematic identities, frames, roles, stories, [and] scripts," (Weber and Dacin 2011, p. 289) and they are drawn into use by people "in varying configurations to solve different kinds of problems" (Swidler 1986, p. 273). Importantly, a cultural repertoire is large and diverse, and its resources comprise "often conflicting ... guides to action" (Swidler 
1986, p. 277). This manifests in people "know[ing] more culture than they use" (Swidler 1986, p. 277) and using culture selectively when confronted with specific kinds of problems.

Cultural strategies of action are patterned ways of drawing on cultural resources, or "general way[s] of organizing action" (Swidler 1986, p. 277), used by members of a culture. Cultural strategies of action enable people to navigate the complexity and ambiguity of their culture's repertoire because they provide ways of "construct[ing] chains of action beginning with at least some pre-fabricated links" (Swidler 1986, p. 277). Cultural strategies of action become familiar to and valued by members of a culture, and they tend to be drawn into use to accomplish a variety of tasks. Harrison and Corley (2011) found that certain cultural strategies of action, such as self-reliance and persistence in the face of failure, were used by employees of Alpinista, a rock climbing company, in diverse circumstances. An executive, speaking of improving Alpinista's IT systems, could equally have been describing how his employees (who were recreational climbers) would scale a rock face when he commented: "We've got grinder personalities: you give it your first shot, if that doesn't work you give it your second shot. If that doesn't work you go again.” (Harrison and Corley 2011, p. 398).

The continued use of certain strategies of action by members of a culture produces the persistence and regularity so often associated with culture. Yet, Swidler (1986) warns that this regularity arises because cultures cultivate skills and habits among their members through the use of strategies of action, not because cultures specify shared values. The regularity of culture is therefore an accomplishment to be explained. Cultural strategies of action may, in some situations or by some people, be repurposed, differently prioritized, or abandoned altogether. Indeed, organizational scholars using the culture as repertoire perspective have shown how employees' skillful use of cultural resources and strategies of action can alter culture, or affirm and maintain it in the face of pressures for change (Howard-Grenville et al. 2011, Kellogg 2011, Rindova et al. 2011). Seen this way, organizational cultures are put to use by their members. Indeed, like routines, cultures can be regarded as performed and their regularities produced in an ongoing manner through situated actions. 
Our inquiry into what happens when organizations covet others' routines and attempt to enact them as their own is therefore best tackled if we regard both routines and cultures as dynamic. This enables a close look at the interplay between cultural strategies of actions and patterns of action that emerge as routines are integrated. And, it permits culture to be more than a conservative force that routines must be tailored to, as culture is enacted by the very people who are skillful at adjusting their actions and enacting multiple patterns as they perform routines. In line with our review of the literature, we arrive at the following research question: How does the use of culture by organizational members shape the unfolding of recognizable patterns of action as a routine is integrated?

\section{Methods}

\section{Research Setting}

Oilco's effort to develop an operational compliance routine provides an excellent setting from which to build theory on how organizations integrate coveted routines that are a poor fit. During the period of our study, Oilco sought to integrate an operational compliance routine already in use by industry peers despite having a culture that was poorly aligned with the discipline demanded by this approach. As a pioneer in Alberta's oil sands, Oilco helped build a new industry by extracting a resource that many doubted would be developed economically. Starting out with one money-losing plant, the company took huge financial risks and invested in new technologies, ultimately leading to decades of rapid growth and its current status as one of the industry's largest players. But with growth came challenges. By the mid-2000s, Oilco was experiencing growing pains in the form of reliability issues and regulatory non-compliance infractions. Investors were pressuring Oilco to reduce the risk of its operations. Oilco's response was to turn to the emerging industry standard of "operational excellence," and, within this, a routine for operational compliance that would enable it to identify its environment, health, and safety (EH\&S) regulatory obligations, ensuring its facilities were designed, built and operated in compliance and that employees completed associated tasks properly. Oilco's effort to integrate the operational compliance routine began in 2009 and remained a key priority throughout our study. Hence, our investigation affords insight into the longitudinal interaction between organizational culture and the integration of a routine. 


\section{Data Collection}

This paper draws from a more extensive data set collected by the first author to capture the cultural antecedents of environmental compliance at Oilco and builds on that data set through additional interviews and observations. During early interviews, she noted considerable reference to an effort towards integrating an operational compliance routine. As the other authors of this paper became involved, their efforts to 'come up to speed' and the questions they asked in grappling to understand Oilco's culture drew our attention to how culture was used and taken up in preparing for and performing the operational compliance routine.

Our primary data consists of five years' worth of interviews, site visits, observations, check-in calls and focus group sessions, as outlined in Table 1. We draw upon 82 interviews with Oilco employees from the most senior managers down to front line operators including employees from several of Oilco's Operations Units, who were involved in active oil production; the Design/Build Group, who were involved in designing and constructing new assets $^{2}$ for future oil production; the Regulatory Compliance Team, who were enabling the development of the operational compliance routine; and the Environment, Health and Safety (EH\&S) group. We also draw on data from four focus groups, 13 site visits (including multiple visits to a key operational site, Northsite, which we reference later in the paper) and 15 regular check-in calls with key informants. Most of these interviews and conversations were recorded and transcribed. In a few cases when it was not possible to record we took detailed notes. Field notes were written within 24 hours of observations. As part of our interactions we also attended social events and had 'offline' conversations with several employees. Lastly, we drew upon secondary data including Oilco's annual reports and sustainability reports from 2001 to 2014 and several internal newsletters to track discussions about operational compliance. It is this entire corpus of data and experience that we reflect upon in this paper.

Insert Table 1 about here

2 At Oilco, assets range from the development of an entirely new facility down to the addition of a new oil tank or the installation of a fence. 


\section{Data Analysis}

We approached our analysis from a broadly interpretive perspective with a focus on accounts of Oilco's efforts to develop and implement the operational compliance routine, and the interaction of this with its cultural repertoire and strategies of action. As is typical for qualitative, inductive analysis, we proceeded through several stages as we worked back and forth between our data and emerging theoretical insights (Charmaz 2006, Locke 2001). Early on, as we independently read the interview data, we were struck by the degree to which informants regarded Oilco's culture as somewhat misaligned with the operational compliance routine, yet expressed great confidence that it, and the larger operational excellence effort, would become, in the words of one, "the dominant paradigm going forward."

We began by coding the interview data using emergent first-order codes that expressed themes in the language of informants (Van Maanen 1979). We attended to both culture and the routine in our coding. We subsequently refined our codes through several systematic passes through the data, adding to, combining, or eliminating codes as we constantly compared the coded passages to each other and to our emerging theoretical insights. Throughout our analysis, conversations with key informants gave us confidence that our developing understanding was consistent with their lived experiences.

Culture coding. Our culture coding sought to capture the ways Oilco informants described and did work in the organization. For example, the codes "entrepreneurial" and "get "er done" were each applied to the statement "[we have an] entrepreneurial mentality that, gee, we are going to grow ... and we will respond to whatever comes along." We found high consistency, even in terms of terminology, in how informants described their culture. Our working definition of culture was consistent with the perspective described earlier, in which culture is regarded as a repertoire of resources and strategies of action are members' patterned ways of drawing on cultural resources, or "general way[s] of organizing action" (Swidler 1986, p. 277). We saw significant alignment between elements of Oilco's cultural repertoire and specific strategies of action. Because strategies of action are most proximally associated with how culture is put to use, our explanations of how culture was used as the routine was integrated focus on these. 
Routine coding. Our routine coding focused on leaders' aspirations for the operational compliance routine, its design, the steps being taken to implement it, and outcomes of these efforts. We discerned the espoused routine (specific articulations of how the routine was intended to work) from statements by leaders and those charged with designing the routine. The operational compliance routine was to be performed across Oilco, in both the Operations Units and the Design/Build Group. Specific artifacts, including a purpose-built IT system, the 'RegCompliance Tool,' were to be used in performing the routine and enabling it to interface across these groups. Our coding also captured the design, use, and patterns of use around these artifacts and among the Operations Units and Design/Build Group. As well, we coded for references to the importance of operational compliance to Oilco, and the routine's fit with the culture. Identifying some gaps in our data, we performed additional interviews and observations to update our understanding of the routine's integration and to compare its use at Oilco's to that of other companies.

Theorizing the interplay of culture and the routine. We noticed that, even as the routine was espoused and supporting artifacts and expectations for it put in place, these bore the marks of Oilco's predominant cultural strategies of action, a process we labelled cultural molding. We also noticed similarities and differences between the espoused routine as articulated by senior leaders and the patterns of action that emerged and were sustained, which triggered us to revisit our data and identify two primary ways in which the enacted routine departed from the espoused routine. In our final stage of analysis, we sought to understand how these distinct patterns of action came about and continued to be sustained. Drawing on our knowledge of the cultural strategies of action and informants' accounts of when and how patterns of action emerged, we developed the constructs of cultural shielding and cultural shoring to capture how distinct patterns emerged, respectively, from using strategies of action to conceal departures from the espoused routine, and from using strategies of action to attempt to uphold the espoused routine's integrity.

\section{Findings: Integrating the Operational Compliance Routine at Oilco}

We begin by describing the essence of Oilco's culture, highlighting its misalignment with the coveted operational compliance routine. Next, taking advantage of our longitudinal data, we describe how Oilco's members' use of cultural strategies of action shaped the routine at two distinct periods of time. First, we 
show how the routine was culturally molded by leaders' and managers' use of Oilco's predominant strategies of action, yielding artifacts and expectations that condoned, rather than suppressed, the continued use of these strategies of action. Second, we show how, five years after the routine's espousal, distinct patterns of action had taken hold and were sustained through the processes of cultural shielding and cultural shoring. These patterns reflected differences in how employees performing the routine drew cultural strategies of action into use when confronted with the mismatch between their predominant strategies of action and those demanded by the espoused routine.

\section{Oilco's Cultural Repertoire and Strategies of Action}

Oilco's cultural repertoire was comprised of stories, scripts and frames related to its experience as a scrappy pioneer developing large-scale engineering projects in remote environments under tight timelines. As one informant observed: "[It's] very much the frontier mentality." Stories of Oilco's past were readily available cultural resources that conveyed the value of hard work and an entrepreneurial mindset, depicting the journey as "a daring venture into an unknown field" and "the biggest gamble in history." One director, explaining the genesis of Oilco's "entrepreneurial spirit” said:

If you ... look at where [Oilco] came from, I mean it had to get out there. It had to prove the technologies. It had to prove it was a viable business. And in doing so, I think it left some other pieces aside.

One of the things "left aside" was a capacity to anticipate or prevent problems. One respondent spoke at length about "our culture of starting things and never really finishing them" and another affirmed:

Oh yeah. You hear lots of colorful wording around that, you know, 'fly by the seat of the pants,' 'firefighting.' It's a very heroic culture. [We know that] we might have unanticipated problems, but we will be able to rise to the occasion.

Typical for its industry, Oilco's production sites were extremely physically isolated from each other and from the company's headquarters, ${ }^{3}$ and shift schedules enabled little or no overlap between front line and managerial employees who shared job titles and roles at a given production site. While others in the industry had developed formalized interactions to overcome this decentralization, informal and personal interactions were favored at Oilco. As one director put it: "Who did what, who decided what, a lot of it...

${ }^{3}$ Headquarters were 700 kilometers or more away from the closest production sites. 
feels like oral record, oral tradition." Another director described hand-offs between groups as "tossing things over the fence," with little follow through. She confided that "[some employees] would just as soon walk down the hall and deal with their buddies, rather than have processes set up."

The ready availability of these cultural resources (stories valorizing entrepreneurial action, and scripts for reacting and informalization) shaped the use of two predominant strategies of action by Oilco's members. One of these, which we label 'get 'er done,' was to complete a task or achieve a goal through sheer effort and pluck. An EH\&S site lead who joined Oilco from a different, highly regulated industry recalled his shock at the "real cowboy attitude of 'get' er done' and, reward[s] for being the hero," noting that "operational discipline and the adherence to standards were almost nonexistent...[People were] very good at putting out fires and not so good at preventing them." When asked during observations how people get rewarded at Oilco, common employee responses included "firefighting," "going for the big win," or "getting things back running again." The 'get 'er done' strategy of action frequently led to redundant, uncoordinated work. One director noted:

Before we know it we have 27 [similar] projects going on ... All well-intentioned and determined and passionate, but uncoordinated, not integrated, and wasting millions of dollars.

A second predominant strategy of action was that of 'follow the leader.' Despite what employees expressed as "a fear of bureaucracy" and "a tendency to try to bypass the bureaucratic mechanisms that do exist," the company was deeply hierarchical. As one informant observed, "If there is one thing that people respond to it is the hierarchy." Another, speaking of front-line employees said, "[What they do] comes down to what [their] boss wants. If [the] boss says get the damn pump in the door, they're going to worry about [the] fastest [way to do that].” In some settings, this strategy of action could appear incompatible with 'get 'er done,' but at Oilco, it was largely compatible. Leaders and managers articulated priorities and employees ensured they were acted on. As an Executive Vice President said: "The [Design/Build] guys are like GI Joe. It's like 'just tell us what to do and we'll go do it."” A director concurred, saying "Eighty percent [of employees' direction] comes from leadership emphasizing what is important to the company." Central to the compatibility of 'follow the leader' with 'get 'er done' was a strong emphasis on 'no 
naysaying.' Taking direction from leaders was about respecting hierarchy, but also about optimism and a can-do attitude. As one director reflected, "if you were a naysayer, you didn’t last [at Oilco]."

In many ways, adopting the operational compliance routine was seen by Oilco's leaders as a way to help steer its culture toward one that supported disciplined, standardized execution of tasks, ultimately reigning in the predominant tendency to 'get 'er done.' One leader summed it up this way:

A lot of cultural attributes that made Oilco a success, you know, do it at all costs, heroism, get in there, fight the fire, make it work... now needed to change. Standard, stable, repeatable processes, [and] creating a culture of compliance to those ... was [the] gap in the organization.

This gap was sorely felt when leaders compared their internal compliance processes with those of their competitors. For example, when asked who in the industry was doing well on operational compliance, the Director of Internal Auditing responded: "All the other big major [oil and gas companies] are more advanced in their governance processes than we are." He added, "compared to [Blue Oil] or [King Oil], [our processes] are an order of magnitude weaker.” In coveting other's processes, Oilco leaders also coveted the cultural strategies of action that supported their performance, including "diligence ... [and] planning." For example, one interviewee said "[KingOil] never built anything commercially till [it] validated all the assumptions." Another, drawing on an oft-used Wild West metaphor, contrasted a competitor's planful “aim, aim, aim, shoot” culture with Oilco's "shoot, shoot, shoot, aim," culture.

In sum, leaders recognized that integrating the operational compliance routine would demand a shift in how Oilco's cultural strategies of action were used; namely, 'get 'er done,' needed to be decoupled from 'follow the leader,' and the latter needed to evolve to include performing repeatable, standardized tasks, not just reacting to the latest priority. Organizational leaders thus envisioned that the 'follow the leader' strategy of action was aligned, and the 'get 'er done' strategy of action was misaligned, with performing the operational compliance routine.

\section{Cultural Molding in the Development of the Operational Compliance Routine}

As Oilco's senior leaders articulated their vision for the operational compliance routine a specific espoused routine emerged. The espoused routine, whose key steps are outlined in Figure 1, was described in strikingly similar language by employees across Oilco. At a high level, the operational compliance 
routine would permit Oilco to identify and maintain a complete database of regulatory obligations, transform these into tasks assigned to specific employees, enable the seamless integration of tasks between groups, and assess the state of compliance at any point in time.

-------- Insert Figure 1 about here

As outlined in Figure 1, Oilco's espoused operational compliance routine involved the use of a software tool (the "RegCompliance Tool") that would be built and maintained by a Regulatory Compliance Team (the "Reg Team") who would work closely with the Operations Units (those operating existing facilities and equipment) and the Design/Build group (those designing and building new facilities and equipment, or 'assets'). By consulting others, the Reg Team would ensure all compliance obligations and associated specific tasks were included in the tool [step 1]. The Design/Build Group would use and update the RegCompliance Tool to ensure compliance during the design and construction of new assets [steps 2 through 4] and coordinate with the Operations unit to handover an updated RegCompliance Tool, ensuring compliance tasks were complete and understood by the Operations Units [step 5]. Managers and employees in the Operations Units would use the RegCompliance Tool to track and complete required compliance tasks, monitor overdue tasks and escalate them to the attention of senior managers [steps 6-9]. The RegCompliance Tool would be updated on an ongoing basis documenting changes in tasks, new tasks resulting from changes in operations, or changes in regulation [step 10]. Finally, to verify adherence to the processes within the routine, an audit team would conduct random checks of all elements [step 11].

Yet, we observed that Oilco's 'get 'er done' and 'follow the leader' strategies of action were drawn into use from the very beginning, shaping how the espoused routine was introduced and employee's expectations about its use. Regulatory compliance was portrayed as an absolute priority by senior leaders ('follow the leader'), but limited guidance and resources were provided to support the routine's development, divulging continued reliance on the 'get 'er done' strategy of action. As the Director of Regulatory recalled, "regulatory compliance came up as the top of the [senior leadership's] list as an initiative that we need to complete as fast as possible." But, as he also explained: 
We all wanted to do the right thing. [But] ...there was no real structure or sequencing as to how we were going to go about doing this. It was just 'everyone go forth and get it done.' (emphasis added) Consistent with 'getting 'er done,' and in line with a cultural repertoire that supported entrepreneurial action and shunned formality, Oilco's senior managers dismissed some of what other companies did as "overly bureaucratic" or too "regimented." Consequently, they set the expectation that the artifacts and procedures supporting the routine would be "based on [recognized] standards, ... [and] benchmarked up against [specific competitors]" but that ultimately an internal team would "build our own Oilco version." As a result, the expectations and artifacts to support the routine's performance tended to reflect and condone, rather than suppress, the use of cultural strategies of action that were misaligned with the coveted routine. We label this process cultural molding.

In turn, we observed that Oilco's enacted version of the routine quickly departed from the espoused ideal of being fully comprehensive and seamlessly integrated, because managers tasked with developing it also relied on their familiar 'get 'er done' strategy of action. For example, the Reg Team was responsible for generating the initial database of compliance obligations and associating them with tasks assigned to specific people ("tasking them"). This was a fairly daunting undertaking, given the sheer quantity and variety of compliance obligations that applied across Oilco's diverse facilities. The Reg Team drew upon their 'get 'er done' strategy of action, focusing on getting items into the database and worrying less about specifying full procedures and associated documentation. As the Director of Compliance explained "It's more about the process of getting [tasks] into the tool," adding, "The actual crafting of the task ... will continue to get better over time." The Reg Team also "never went back in history [to uncover all prior commitments]. ... The concept was start from today and go forward," (Senior EH\&S Manager). As a result, the artifact being built to enable the routine was at best incomplete.

The senior leaders' directive to 'follow the leader' and aggressively develop and integrate the operational compliance routine only reinforced the sense of urgency that historically brought the 'get 'er done' strategy of action to the fore. A Design/Build Group Manager recalled there was "a real push ... right to the highest levels in the corporation to roll this out as fast as humanly possible to elevate our 
game." This meant that the Reg Team was overwhelmed with developing the RegCompliance Tool and tasking it for the Operations units, leaving the Design/Build Group on its own to work out how to enable its portion of the routine. As explained by a Design/Build Manager, “[The Reg Team] said - [we] don't have the resources to do that now ... So there was an agreement that [we] would take on the work that would be required to look at [integrating the compliance routine in Design/Build].”

Just as familiar cultural strategies of action were drawn into use, molding the artifacts and expectations that would support the routine's performance, departures from the espoused routine were accommodated by these same strategies of action. Whereas in another company we were told that the enormous task of building a complete master list of compliance obligations had, "within six months ... collapsed under it's own weight it" at Oilco, employees soldiered on reflecting their unrelenting optimism ('get 'er done') and no naysaying ('follow the leader'). In sum, cultural molding influences a routine by shaping the artifacts and expectations associated with its performance; in this way, organizational members' use of culture shapes a routine's integration even before the routine is repeatedly performed.

\section{Cultural Shielding and Shoring in the Enactment of the Operational Compliance Routine}

As we systematically compared the espoused routine to the enacted patterns of action it spawned, we found important deviations from the espoused, as depicted in Figure 2. In some instances, an entire step in the routine was missing, what we call a void, and in its place was a workaround (Alter 2014, Tyre and Orlikowski 1994). For instance, in Steps 3 and 4, Design/Build employees are meant to track, complete, and document the completion of compliance obligations using the RegCompliance Tool. Instead, we found a workaround in which they made use of separate spreadsheets during the design and construction period and only repopulated the RegCompliance Tool when construction was complete. In other steps, we found that employees were attempting to perform the step as espoused, yet they were not able to do so. We labeled these hindered performances. A hindered performance occurs when employees, making use of a cultural strategy of action aligned with the espoused routine, are unable to fully perform a step in the routine because their own performance relies on others who continue to draw on a misaligned strategy of action. For instance, in Step 6, the Reg Team and Operations Units were meant to work together to 
translate compliance obligations into a well-specified set of ongoing tasks that would be assigned to specific employees. Instead, the Reg Team was hindered in its ability to perform this step because some employees in the Operations Units preferred a 'get 'er done' approach to getting their work done, and were unwilling to be held accountable for defining and performing specific tasks.

------- Insert Figure 2 about here -------

The patterns of workarounds and hindered performances had given rise to additional work to conceal or compensate for these deviations from the espoused routine. We call this additional work cultural shielding and cultural shoring. Our terms draw upon a metaphor of how construction workers address the potential for a sidewall to collapse during excavation work. Shielding does not focus on upholding the wall, but instead puts structures in place that allow work to proceed and protect workers in the event of a collapse, whereas shoring involves workers adding additional support to uphold a sidewall and prevent its collapse. Thus, shielding is about protecting the worker (and the work) from the potential failure of a wall, whereas shoring is about maintaining the wall. By analogy, we regard the espoused routine as the 'sidewall,' and the cultural strategies of action as the 'tools' employees draw into use as they perform the routine (working on/around the wall). Employees may attempt to shield workarounds by using strategies of action to conceal voids in their performance of the espoused routine, or they may use strategies of action to shore-up hindered performances of the espoused routine. In each case, additional cultural work is involved, but cultural shielding simply conceals voids and protects workarounds from scrutiny. It does not attempt to uphold the routine, much like erecting shielding during construction is focused on allowing work to proceed rather than maintaining the integrity of the wall. On the other hand, cultural shoring attempts to uphold the integrity of the espoused routine by compensating for hindered performances, much like shoring a sidewall seeks to prevent its collapse. We describe these processes below, explaining how the use of cultural strategies of action both trigger the need for, and enable, shielding and shoring.

\section{Cultural Shielding}

Cultural shielding was triggered by employees defaulting to using a cultural strategy of action ('get 'er done') rendered out of alignment with the espoused routine, and hence creating voids and workarounds 
for one or more steps of the espoused routine. Cultural shielding refers to the subsequent process of employees leveraging a strategy of action that is more aligned with the espoused routine, in order to camouflage the voids and protect their workarounds from scrutiny. For example, citing fears they would be "burdened down in bureaucracy," and the lack of readiness of the RegCompliance Tool, members of the Design/Build Group defaulted to their 'get 'er done' strategy of action and introduced a spreadsheet workaround that subsequently became an accepted pattern of action. They then engaged in a pattern of shielding that workaround to protect it from scrutiny. As shown in Figure 1, in Step 2, the Design/Build Group is meant to use the RegCompliance Tool to identify the compliance obligations that are relevant to the design of the new asset. One Design/Build Manager explained how they do, in fact, perform this step:

[The RegCompliance Tool has] a massive checklist of potential regulatory approvals or permits that you may or may not need on a job. So the way it works is if you're a project manager you sit down with your lead engineer on your job and you go through a checklist before you start the project. You go through and you start ticking off all these approval documents. ... It'll say okay, 'do you have fuel gas piping?' Yes. Okay, well then you need a gas permit from [the agency]. Just tch, tch, tch, tch, [checking sound] you go through the whole list.

In contrast, in Steps 3 and 4, Design/Build employees were meant to track, complete, and document the completion of compliance obligations using the RegCompliance Tool. Instead, as depicted in Figure 2, they started building smaller 'Asset Registries' that consisted of their own spreadsheets. As another Design/Build Manager explained "because the RegCompliance Tool has not been up and running ...we started with the spreadsheet approach, we've got to continue using the spreadsheet approach in the short term." Even after the introduction of the RegCompliance Tool, spreadsheets became regularly used across the group for all new assets. Design/Build Managers would "[consult] the RegCompliance Tool [Step 2], take a subset of it for the asset and dump it in Excel [with] the basic requirements ... [make] a bunch of columns and [note] who's responsible and when they're supposed to do it." Because these were "nothing more than just spreadsheets that hang out in someone's hard drive" (EH\&S Manager), they were not visible to others in the organization nor connected to the RegCompliance Tool with which they were supposed to integrate [Steps 3, 4, 5 and 10 in the espoused routine]. 
Many in the Design/Build Group regarded the pattern of working around the routine by developing and using their own Asset Registries as a legitimate enactment of the operational compliance routine. However, at least one Design/Build Group Asset Manager admitted to knowing this pattern was inconsistent with the espoused routine, but, as is typical for workarounds (Tyre and Orlikowski 1994), he justified this departure in terms of how it enabled him to get his job done:

If I was ... the director of this whole group, I may want to see [the RegCompliance Tool] rolled out just to make sure I know that everyone's doing what they need to do. For me as an asset manager I don't care about everyone else's approvals, I only care about my own. So the Excel [spreadsheet process] works great for me. ... [But] if you're in charge of compliance at Oilco, probably you want that [Tool] I guess.

Yet, the spreadsheet workaround was accompanied by a void in the performance of the espoused routine that would prevent others from doing subsequent steps of the routine. Design/Build employees could not completely ignore this void, especially because leaders continued to articulate the priority of following the espoused operational compliance routine. Steps 4 and 5 in the espoused routine portray a seamless integration of the Design/Build Group's work with the RegCompliance tool with its subsequent use by Operations Units. To shield their workarounds from scrutiny and conceal this void, Design/Build employees drew on the 'follow the leader' strategy of action and developed a pattern of taking the output of their workarounds (compliance obligations held in spreadsheets) and 'inserting' them back into the routine when it came time to hand a newly built asset over to Operations to run it [Step 5]. Shielding therefore involved employees skillfully using a cultural strategy of action aligned with the espoused routine to protect the workaround prompted by defaulting to using a misaligned cultural strategy of action.

Shielding appeared to be effective at deflecting scrutiny over the workarounds, as those outside the Design/Build Group recognized Design/Build's workaround as a pattern of action associated with the performance of the operational compliance routine. For example, a Reg Team member noted: "[Design/Build] have a process set up and its very spreadsheet driven. ...[It] exists and is very aligned ... whether you have the [RegCompliance Tool] or not, that process is there." While others in the organization recognized the difference between the espoused routine step and Design/Build's workaround, they were largely acquiescent. During an interview, one author articulated the pattern of action as she had 
been told by earlier informants: "[So Design/Build will] dump the information from the RegCompliance Tool into an Excel spreadsheet and then use that spreadsheet for [the] entire [asset build period], ignoring the fact that the RegCompliance Tool is changing. Then at the end of it, [you'll] dump all of that back again to the RegCompliance Tool, is that right?" The interviewee affirmed that pattern, adding "It was 'get 'er done,' but not in a fashion that really worked."

A second illustration of an emergent pattern of workarounds occurred within some Operations Units when some employees worked around Step 7 of the routine, in which they were meant to complete tasks, document their completion in the RegCompliance Tool and, as required, attach supporting documentation. As explained by the Director of EH\&S in one of the Operations Units, this espoused step "forces people to do the tasks that are assigned to them because if not, they get hounded and it gets escalated." Yet, we found that some employees saw the requirement to document the completion of each little task as "hitting a fly with a sledgehammer." In response, some employees defaulted to 'get 'er done' and developed the workaround of going into the RegCompliance Tool at the start of the year, opening all their tasks for the year and marking them as complete. This clearly departed from the spirit of Step 7 of the espoused routine, yet this workaround was permitted by the earlier cultural molding of the routine, namely that the artifact had been built in a way that enabled the continued use of the 'get 'er done' strategy of action. An Oilco manager contrasted this workaround with his experiences performing the same routine at MonoOil:

When I was in [MonoOil], ... [if] I complete [a] task, I go into the system and I click 'done' [but] the system does not record it as done. It sends it back to my supervisor and my supervisor has to confirm that he has seen that I have done it and he agrees that it is done. And only then can the system record that action as having been [done].

While some employees worked around the RegCompliance Tool by documenting tasks before they were completed, these employees were unable to shield this workaround from scrutiny. At the close of our data gathering, the Reg Team had altered the Tool so that a task closed more than 90 days prior to its due date was flagged and, reflecting efforts to realign the routine's performances with 'follow the leader,' such tasks were reported directly to senior leaders. 
In summary, we found patterns of action in the enacted routine that emerged from employees defaulting to the 'get er done' strategy of action, which was misaligned with the espoused routine. This left voids in certain steps of the routine and in their place employees performed workarounds. Some employees were able to leverage a cultural strategy of action aligned with the espoused routine ('follow the leader'), to subsequently take actions to shield their workarounds. However, cultural shielding was not an inevitable response to workarounds, as illustrated by the example of the detection of employees marking all of their tasks as complete at the beginning of the year. Indeed, cultural shielding entails doing additional work beyond simply working around performing a step in the routine.

\section{Cultural Shoring}

Cultural shoring was triggered by employees using a cultural strategy of action ('follow the leader') in alignment with the espoused routine, but discovering that they were unable to enact the steps as espoused because the misaligned ('get 'er done') strategy of action was still in use in the organization, hindering the performance of particular steps of the routine. Cultural shoring refers to the subsequent process of employees reverting to a strategy of action that is out of alignment with the espoused routine and engaging in extra actions in an effort to uphold the integrity of the routine to compensate (and sometimes overcompensate) for their hindered performance. With no viable alternative strategies of action to draw upon, employees revert back to using a misaligned strategy of action ('get 'er done') even though the resulting patterns of action are not particularly useful in serving the routine's intended goals, and primarily serve to maintain the appearance that the routine is being performed as espoused.

One example of cultural shoring was triggered when employees experienced hindered performances in Step 6. In this step, the Reg Team and Operations Units are meant to translate compliance obligations into a well-specified set of tasks that are to be assigned to specific employees. Members of the Reg Team drew on the 'follow the leader' strategy of action, aiming to perform this Step closely in line with what was espoused. As described by a Compliance Manager from the Design/Build Group, "they went through a major tasking exercise ...they took every one of the relevant regulations and directives and then went through every line of it. And if there was an action associated with it then they put that in the 
[RegCompliance Tool] along with responsibility, frequency, all those things." However, as the process of tasking proceeded, it became evident that assigning well-specified tasks to employees was more difficult than initially anticipated. Many of those who were tagged with compliance tasks continued to rely on using the 'get 'er done' strategy of action, favoring getting their 'real' work done over signing up for compliance task assignments. A Senior Manager of EH\&S said:

So I learned that when we task stuff within the [RegCompliance Tool] - some Operations staff got a little bit frustrated saying 'I don't know why I got tagged with this particular compliance task.' And trying to take that task and reassign it to somebody else takes a bit of time because you're trying to find ownership ... [It] takes a bit of time to actually get the new owner to take it on.

Hindered in their performance of Step 6 of the espoused routine because of the challenges of tasking, but eager to demonstrate to leaders that they were on track, the Reg Team reverted to the 'get 'er done' strategy of action. Adding new tasks into the RegCompliance Tool became an accomplishment in and of itself, with the emphasis shifting to completing the tasking for particular Operational Units without much regard to whether the workloads associated with these tasks would be realistic. An EH\&S Director said:

Here's what [the Reg Team does], whether it works or not, ...The [RegCompliance Tool] was done for [our Operation]. There were 750 [tasks listed]. My name is beside 500 [of those]. I went to the first meeting and freaked out because no person can handle 500 items. My feedback to the team was '...The process is broken, because nobody can handle 500 tasks. We have to break it down ... and assign different people.' ... [The Reg Team's response was] 'Nope, we're done.'

Reverting to 'get 'er done' primarily served to attempt to uphold - or shore up - the hindered performances of a step in the routine, making the step look complete without it actually being performed in a way that enabled its interdependency with others, or was in line with the spirit of the espoused routine. An Operations Unit EH\&S Manager explained how the Reg Team had come to perform tasking [Step 6] and its impact on how others could perform the routine: "[They say] 'We did our part ... after that, I hand it over to you.' Whether it's effective or not, get 'er done." He then added, "effective or not is not necessarily a [measure] of success." Performing this step had evolved into demonstrating that the tasking was complete to enable going live with the RegCompliance Tool. Signalling that others were aware of this pattern, a Director of Compliance spoke of his desire to have the Reg Team not simply get the RegCompliance Tool fully populated with tasks, but do it right, saying: 
I'm challenging them ... its not just about getting things into the tool. This should not be a checkthe-box exercise ...I've got four senior regulatory assessors, bright guys with good operations experience, and there's more value that they can be adding. [But the Reg Team is] trying to crank through ...[saying] 'we have 900 tasks to do and [we] did 'em all within the schedule, yahoo.'

A second illustration of an emergent pattern of hindered performances and their cultural shoring was evident in Step 10 of the espoused routine, where Operations managers are meant to update the RegCompliance Tool to include changes in tasks or new tasks stemming from changes in operations. Again, those responsible for updating the tool met with resistance from Operations employees who, still relying on the 'get 'er done' strategy of action, would resist the creation of new tasks and were reluctant to take the time to properly define them. For instance one manager lamented "I don't want to overload my people to task everything, because really they're there to support the operation ... It isn't really a good use of their time." With the performance of Step 10 hindered, yet under pressure to continue demonstrating they were 'following the leader,' those responsible for updating the tool reverted back to the 'get 'er done strategy of action and began shoring-up the shortcomings in their performance of Step 10, to maintain the appearance of enacting the espoused routine. They compensated (even overcompensated) for their hindered performances through additional, effortful actions such as continuing to update the tool with tasks, even if the tasks were poorly defined or lacking in proper detail. As one EH\&S Manager noted, "a task could be created that was gibberish and no one would ... identify that it was out of place."

In summary, we observed a pattern in which employees started by drawing on the 'follow the leader' strategy of action, which was in alignment with espoused routine, to perform certain steps. However, because the misaligned strategy of action (get 'er done), was still being broadly used, employees were hindered in their abilities to perform these steps as espoused. Faced with hindered performances, and no viable alternative strategies of action to draw upon, these employees reverted to the strategy of action misaligned with the espoused routine and engaged in actions in an effort to compensate for and 'shore-up' their performances of these steps. This cultural shoring involves concerted work that signals employees' adherence to letter of the espoused routine yet departs from its spirit. 


\section{A Counterpoint - Redeploying Strategies of Action}

The findings outlined above demonstrate that organizational members tend to continue to draw on familiar cultural strategies of action, shaping how an integrated routine becomes enacted differently from how it is espoused. Here, we provide a contrasting example from one of Oilco's Operations Units that signals that these dynamics are not inevitable and that there is the potential for an alternative path. The case of Northsite helps demonstrate how a savvy management team or other employees can redeploy cultural strategies of action in service of integrating a desired routine, even when it is not a cultural fit. In contrast with other Operations Units, Northsite was viewed as having more successfully integrated the operational compliance routine. Our observations at Northsite suggested that the enacted patterns of action at this facility closely resembled the espoused routine. Employees were using the RegCompliance Tool to monitor and complete compliance tasks (step 7 of the espoused routine) and working with the Reg Team to improve the tasking process. As well, supervisors were tracking and reporting on the status of tasks (step 8) and senior leaders were monitoring and following up on overdue tasks (step 9). While onsite, we observed a number of such instances of these patterns. For instance, a Northsite Vice President demonstrated how "I go in and look at the tool ... and I can see everything for the next while ... how complete [tasks] are or if they're still open."

Northsite's Senior Vice President attributed the successful enactment of the routine to the site leadership's efforts to make operational compliance "a way of life," in contrast to other Operations units where, "it has been viewed somewhat as a project" that they needed to 'get done.' Central to making operational compliance a way of life at Northsite was countering the 'get 'er done' strategy of action through Northsite's leadership carefully redeploying the 'follow the leader' strategy of action. Rather than hoping that employees would leave aside the 'get 'er done' strategy of action in order to perform the routine, Northsite's leaders actively suppressed it. For example, whereas previously untidy and chaotic control rooms and workspaces were the norm, senior leaders sanctioned this behavior and began praising employees for keeping their areas tidy. They associated the 'follow the leader' strategy of action with compliance and accountability, not simply responding to expressed priorities. For example, senior leaders 
leveraged the cultural tendency to 'follow the leader' by markedly increasing supervisors' presence on site for required observation hours. They also elevated the status of EH\&S managers so front line employees were aware that they had "the ability to shut down the operations" if anything was out of compliance. In contrast to other Operations Units that reverted to 'get 'er done,' Northsite managers engaged in the "slow, painful work [to populate the RegCompliance Tool] ...one requirement at a time, identifying ... who gets the task and at what frequency" (Senior Manager, EH\&S). Assigning these tasks made salient accountability and ownership for them. Finally, leaders devised and enforced metrics that would incent following these leader actions. For example, they began to track the percentage of overdue tasks appearing in the RegCompliance Tool and tying that metric to site managers' year-end incentives. One manager explained that this was done "at Northsite [and] so far only at Northsite."

These new ways of 'following the leader' took hold in people's day-to-day actions. The Executive Vice President for Northsite said: "I've now adopted the process where if there's any non-compliance I actually personally follow up with the people involved ...I'll send an email to them and I'll copy every single one of their leaders." Changes showed up in the mundane - as when a leader spoke with pride of seeing an operator mopping the control room floor - and in the less mundane, as when a compliance inspection found only two small issues, where normally comparable sites would have a "long list."

In contrast to elsewhere in Oilco, Northsite's leadership worked to get ahead of possible workarounds and hindered performances by consciously shaping the artifacts and expectations that would support the routine's performance in a manner aligned with the espoused routine. They redeployed the cultural strategy of action aligned with the espoused routine, suppressing the strategy of action misaligned with it. The Northsite example demonstrates that cultural strategies of action can be skillfully redeployed and that, while patterns of action that depart from an espoused routine might be common when a coveted routine is integrated, they are not inevitable.

\section{Discussion}

We began our study with the goal of understanding how organizations integrate routines that are a poor fit. Organizations regularly covet others' routines and seek to enact them in an effort to adopt "best 
practices." Pressures to adopt others' routines only increase as, for example, for-profit organizations seek to become more socially or environmentally responsible, or public organizations seek to become more customer-centric. The integration of routines that are a poor fit for an adopting organization is an important phenomenon, yet we lack understanding of how this process unfolds (Friesl and Larty 2013, Rerup 2004). Prior work signals that the integration of routines is influenced by an organization's culture. Work that regards routines as whole entities asserts that they must match an adopting organization's culture or be customized to match it (Ansari et al. 2010, Winter and Szulanski 2002). Work that regards routines as effortful accomplishments that have a generative quality similarly perpetuates an image of culture as a relatively stable force that shapes how routines are taken up; culture might thwart adoption of new routines (Bruns 2009, Reynaud 2005) or enable the flexible performance of routines so they can be adapted to local or temporary conditions (Canales 2013, Tucker and Edmondson 2003).

Analyzing Oilco's integration of the operational compliance routine over a five-year period, we found that an organization's culture plays a more active and variable role in shaping the integration of routines than is suggested by prior work. By considering culture as a repertoire or "toolkit" from which organizational members construct strategies of action (Swidler, 1986), our analysis captures how cultural strategies of action are differently put to use by different people. This led to distinct actions being taken, and diverse patterns of action emerging as the routine was integrated. Some of these patterns closely matched those of the espoused routine, while others did not. Departures from the espoused routine were accompanied by extra patterns of action that served to either shield these departures from scrutiny, or shore up shortcomings exposed through trying to perform the routine as espoused.

Overall, our analysis reveals that integrating a routine can lead to the repeated performance of more complex patterns of action than those originally espoused, because additional work is done by employees as they try to accommodate the misalignment of their culture with the espoused routine. This is different from outcomes previously identified in the literature, of either the impoverished enactment, or "faux replication" (Winter and Szulanski 2001, p. 732) of a routine that is a poor fit, or its customization. By considering how organizational members use culture as they integrate a routine, our analysis contributes to 
the routine dynamics literature by showing new ways in which routines can be considered effortful accomplishments. Routines are effortful because it takes effort to perform them (Pentland and Rueter 1994); reproducing "the same routine" frequently requires that people make adjustments in their situated performances (Feldman, 2000, 2015). Our analysis shows that the actions taken in performing a routine are simultaneously actions that draw on cultural strategies of action, and that considerable effort is expended by organizational members to integrate and repeatedly perform a routine using cultural strategies of action that are poorly aligned with it. We contend that the complex enacted patterns of action, and the extra work we observed to conceal and compensate for them, are not unique to Oilco's integration of the operational compliance routine. It is likely that newly adopted or even long-standing routines are similarly burdened by additional activity in other organizations as members work to perform routines while simultaneously and skillfully performing their organization's cultures, schema (Rerup and Feldman, 2011), or even power relations (Zbaracki and Bergen, 2010). Accordingly, our theorizing corrects a tendency to see routines as dynamic but the contexts within which they are enacted as relatively stable. We next summarize our main theoretical insights into the process of routine integration and then discuss implications of our work for the nature of routines as truces and the embeddedness of routines.

\section{Cultural Processes during the Integration of Routines}

As an organization integrates a routine that is a poor fit, its members tend to continue to draw on familiar cultural strategies of action shaping how a routine is performed, through influence at several stages. First, cultural strategies of action are drawn into use even as organizational leaders articulate an espoused routine, convey expectations about how it will be integrated, and enlist employees in developing artifacts to support the routine's performance. We label this early process one of cultural molding, which, in the absence of explicit efforts to suppress cultural strategies of action that are misaligned with the routine, inconspicuously shapes the artifacts and expectations that will support the routine's ultimate performance. This is because cultural strategies of action are tenacious. People "are reluctant to abandon familiar strategies of action for which they have the cultural equipment" (Swidler 1986, p. 281), and even those who aspire to change are often culturally ill-equipped to do so. For example, leaders perpetuated and 
implicitly condoned the continued use of both the 'follow the leader' and 'get 'er done' strategies of action when they called for employees to, as quickly as possible, develop an IT tool to support the routine's performance that was "made in Oilco," as opposed to adopt a more "regimented" and standardized tool used by their peers. This choice had ongoing repercussions as Oilco's IT tool permitted the continued use of the 'get 'er done' strategy of action in performing the routine (e.g., by permitting workarounds to record completed tasks before they were done). While prior work shows that culture can stymie the uptake of a routine when employees fail to perform it as espoused (Bruns 2009, Reynaud 2005), cultural molding draws attention to how the espousal and design of a routine can already reflect the use of an organization's culture, which in turn delimits how the routine can ultimately be performed.

------- Insert Figure 3 about here -------

Subsequently, an enacted routine emerges that also reflects the ongoing use of predominant cultural strategies of action. Yet, because people "know more culture than they use" (Swidler 1986, p. 277) - or, put differently, have a number and variety of "tools" (or strategies of action) in their cultural "toolkit," different people might draw differently on these. We found two main pathways, shown in Figure 3, through which employees' uses of cultural strategies of action yielded distinct, repeatedly performed patterns of action. The first pathway unfolds when employees asked to perform the routine default to drawing on a strategy of action that is misaligned with the espoused routine (represented by the light shaded circle and topmost arrow in Figure 3). In essence, because they show up with the wrong 'tool' (strategy of action) for the task (steps in the routine), they are unable to perform the step(s) of the routine as espoused. Instead, using their favored 'tool,' these employees work around the step to get their work done, creating an accompanying void in the espoused routine. Knowing the void will prevent others from continuing with the next step in the routine and to protect their workaround from scrutiny, these employees subsequently draw into use an alternative 'tool' (strategy of action) that is aligned with the espoused routine (see the dark shaded circle and dark arrow in Figure 3) and engage in actions that enable the next step in the routine to proceed. We label this additional work of protecting workarounds cultural shielding. 
The second pathway unfolds when employees, asked to perform the routine, start out drawing on a strategy of action that is aligned with the espoused routine. However, as they do so, and in the absence of managerial efforts to suppress the use of misaligned strategies of action, they discover that they can only enact hindered performances of a routine step because at least some of those involved are drawing on a misaligned strategy of action. Using the tool analogy, some employees bring the 'right' tool for the task, while others can't help but carry the 'wrong' tool even when they might intend to use the 'right' tool. Because their actions are interdependent, the work of employees using the 'right' tool will be inevitably hindered by that of others who have been unable to set aside the 'wrong tool.' In response to hindered performances, these employees revert to a strategy of action that is misaligned with the espoused routine, in essence picking up the 'wrong' tool, and performing extra actions in an effort to maintain the appearance of enacting the espoused routine. (In Figure 3, we depict the tethered tools/strategies of action as a circle with both shades). We label this additional work of maintaining the appearance of enacting the espoused routine cultural shoring as it seeks to uphold the integrity of the espoused routine.

While each process involves the continued use of a strategy of action misaligned with the espoused routine, cultural shielding and shoring are different responses to different emergent patterns of action. Cultural shielding is triggered when employees default to using a strategy of action misaligned with the espoused routine, generating emergent patterns of voids and workarounds; cultural shielding occurs when employees skillfully use a strategy of action aligned with the espoused routine to conceal the voids, protecting the workarounds but making no attempt to uphold the espoused routine itself. Cultural shoring is triggered by employees attempting to use a strategy of action aligned with the espoused routine but being hindered in their performances by others; cultural shoring occurs when these employees revert to using a strategy of action misaligned with the espoused routine as they try to compensate for of hindered performances and seek to uphold the routine's integrity by maintaining the appearance of performing it. Together with cultural molding, the processes of cultural shielding and shoring add considerable nuance to our understanding of the relationship between culture and the integration of routines that are a poor fit. 
First, while the process we describe is not incompatible with work from the entity perspective, which argues that routines and practices are frequently customized in order to be integrated (Ansari et al. 2014, Szulanski 2000), our account suggests that changes made to a routine as it is integrated are the outcome of a distributed process that unfolds as employees differentially draw cultural strategies of action into use, and react to emergent patterns of action that arise as they perform the routine. Accordingly, our process moves beyond a binary depiction of transfer or failed transfer (Lozeau et al. 2002, Winter and Szulanski 2002) and demonstrates that several patterns of action, differing in how closely they resemble the espoused routine, can be sustained simultaneously as part of an integrated routine.

Second, our process builds on the limited existing work that considers routine integration from a process perspective. Deliberate actions taken in the process of integrating a routine can generate desired patterns (D'Adderio 2014, Edmondson et al. 2001). We lend additional insight into the development of these patterns, by paying attention to how the use of cultural strategies of action shapes the patterns that emerge, and to how the mismatch of these patterns to an espoused routine triggers further culturallyinformed action. We show how employees used their cultural 'tools' to conceal or compensate for differences between emergent patterns of action and the espoused routine. In other words, by attending to how people use their organization's cultural repertoire, our analysis helps explain both why certain emergent patterns are generated when a routine is integrated, and how employees work to uphold (or not) the espoused routine while also upholding their culture.

Finally, we build on prior work that considers the interaction between culture and practices when low-fit practices are adopted (Canato et al. 2013, Lozeau et al. 2002). Somewhat surprisingly, the emphasis in this literature has been largely on cognitive mechanisms - leaders sensegive and members sensemake around practices (Canato et al. 2013). By contrast, and consistent with the routine dynamics perspective, our cultural explanations focus on actions. We show how the actions taken to perform a routine draw cultural strategies of action into use, which gives rise to emergent patterns of action, and in turn demands further work that draws additional cultural strategies of action into use. 
Future work could explore the mechanisms of cultural molding, cultural shielding, and cultural shoring in other settings. While Oilco's strategies of action ('get 'er done' and 'follow the leader') might be seen as particularly conducive to, respectively, working around the espoused routine and subsequently seeking to camouflage the workarounds, or engaging in additional work to shore up hindered performances, we believe our findings about the role of culture in the process of routine integration can generalize to other settings. Any time a cultural strategy of action is misaligned with an espoused routine as in all cases of integrating routines with low cultural fit - we can expect at least some employees to default to using the misaligned strategy of action, spurring efforts to work around the routine as espoused. For example, Reynaud observed a similar pattern of employees defaulting to their "way of doing things" (2005: 864) - relying on quick visual inspection to inventory and prioritize tasks in the Paris Metro repair workshop - and often working around the use of a newly imposed procedure for task assignment.

Similarly, we can expect in other settings that employees who primarily draw on a strategy of action aligned with the espoused routine might be hindered by their interdependency with others who continue to use a misaligned strategy of action. For example, in her study of the integration of new safety routines in university laboratories, Bruns (2009) found that employees who tried to follow the espoused routine, by assigning accountability for safety compliance tasks in collective spaces, were thwarted by others. Most scientists continued to draw on strategies of action that helped them ensure the integrity of their experiments and advance their personal scientific objectives, but lacked cultural tools associated with a commitment to a collective enterprise that would have eased their adoption of the safety routines.

It is important to recognize some boundary conditions to the transfer of our theorizing to other settings. First, we explored an organization in which employees' cultural strategies of action were rather tenacious, as well as broadly shared across units and hierarchical levels. The scope for variations in the use of strategies of action might therefore have been somewhat more limited than one would find in other settings. As well, this organization was known to be somewhat unreflective on its own culture, a shortcoming that several managers pointed out to us. In other settings, existing cultural strategies of action might be more readily redeployed as a routine is integrated, or the process of integrating the routine might 
gradually introduce new strategies of action to the cultural repertoire (Canato et al., 2013). In our case, the possibility for such change was found only in pockets where there was explicit intervention, such as Northsite. Future work can explore further how the combinations and sequencing of predominant strategies of action shapes routine integration in other settings.

\section{The Nature of Routines as Truces}

The processes of cultural shielding and shoring also suggest a new way of thinking about routines as truces. While prior work asserts that truces settle "the underlying problem of diverging member interests" (Nelson and Winter 1982, p. 956), and hence trains attention on power relations and latent conflict underlying routine dynamics (Cacciatori 2012, Pentland and Feldman 2005, Zbaracki and Bergen 2010), our case demonstrates the role of culture in these truces. Despite people enacting the operational compliance routine in different ways, we did not see latent or overt conflict. In contrast, it was surprising to us how apparently complicit people were in accepting the patterns of action that had emerged and the ways in which cultural strategies of action were used to shield or shore up departures from the espoused routine. Cultural shielding and shoring were manifestations of a "cultural truce" that enabled the routine to continue to be performed, despite voids/workarounds and hindered performances. Unlike a political truce in which differing interests are suppressed until the truce is strained too far (Zbaracki and Bergen 2010), a cultural truce arises from the fact that culture dynamically accommodates ambiguity through its members' selective use of strategies of action. As Swidler (1986) asserts, cultures frequently comprise "diverse, often conflicting, symbols, rituals, stories and guides to action" (p. 277). Cultural strategies of action, accordingly, are often leveraged in ways that normalize, rather than problematize, ambiguity.

Moving from only a static, political understanding of routines as truces that rely on conflicting interests and their suppression, to a more dynamic, cultural understanding of routines as truces that derive their flexibility from people's skillful use of strategies of action can add to explanations for the multiplicity of goals, patterns, and performances that comprise routines (Canales 2013, D'Adderio 2014, Turner and Rindova 2012). Further, seeing routine performance as manifestations of cultural truces directs attention to the effortful nature of routine performance. It takes effort to put cultural strategies of action to 
use in ways that sufficiently uphold both a routine and the culture through which it is enacted. Integrating a routine that is a poor fit may well demand the kind of patchy and effortful process that we observed, because it creates 'good enough' routine performances that are realistic within a culture, rather than attempting to force a strained settlement. Yet, taken too far, cultural truces may also have unintended consequences, for instance, future work could explore their potential to contribute to the development of mock bureaucracies (Gouldner, 1954, cited in Hynes and Prasad 1997).

\section{The Embeddedness of Routines}

Finally, our work extends and adds nuance to understandings of how routines are embedded within their organizational contexts. The concept of routines' embeddedness (Howard-Grenville 2005) derives from the observation that routines are performed in the presence of other routines (Narduzzo et al. 2000), and other structures or systems of meaning (Feldman 2003, Gersick and Hackman 1990). Practices, artifacts, and expectations that contribute to routine performances may simultaneously generate or guide other aspects of organizing, and significant "overlap" ${ }^{4}$ " of these is predicted to constrain a routine's change over time (Howard-Grenville 2005, p. 631). A central insight of our theorizing is that when employees take action to perform a routine their actions simultaneously draw into use cultural strategies of action. This suggests embeddedness is not so much a state in which routines are enacted against a somewhat stable backdrop of other structures, but is instead a process through which routines are co-constituted with other generative systems. A more fitting label might be "entanglement" because it draws attention to the inherent inseparability of "things," and the centrality of process to organizational life (Orlikowski and Scott 2008). Other routines scholars have explored the co-constitution of routines and other structures. For example, Rerup and Feldman demonstrate how organizational level schemata, "knowledge structures that organize past and future experiences" (2011, p. 578), coevolve with organizational routines in a newly established organization. As well, D'Adderio demonstrates that material and social aspects of organizing

\footnotetext{
${ }^{4}$ Sewell uses the term "overlap" to describe the multiplicity and intersection of structures that shape social life (1992).
} 
can be reconfigured to enable certain types of routine performances, leading her to argue that "routines are not simply embedded in context, they are also enacted through context” (2014, p. 23).

Our attention to culture offers additional lines of sight to these perspectives on co-constitution and embeddedness. The processes of cultural shielding and shoring illustrate the ongoing interaction of culture and routine performances, where both are grounded in action. Drawing a cultural strategy of action into use while performing a routine yields a pattern of action (workarounds or hindered performances) enabled or constrained by that strategy of action. In turn, the emergent pattern of action within the routine begets further cultural work as people draw on strategies of action to shield or shore up the pattern. The back and forth between culture and routine performances suggests that neither can really be regarded as 'in the background' to the other.

As well, this perspective on culture helps explain how the embeddedness of routines can at times be an enabler of change, and at other times a constraint on it. Skillful employees can redeploy cultural strategies of action to enable change, as at Oilco's Northsite operation. People seeking to change a routine will be more successful if they are able to expose how existing cultural strategies of action might impede a new routine, and/or are able to redeploy one or more existing strategies of action in service of the new routine. Conversely, lack of awareness of the need to suppress familiar cultural approaches, or lack of capacity to do so, may forestall the adoption or planned change of routines. For example, Feldman finds that a planned routine change does not take hold as expected in a university housing organization, where the routine was "a relatively minor part of a larger routine, managers were pushing the change, and no one was against it" (2003, p. 730). In this case, performances of a new budgeting routine were at odds with how employees understood their work, and hence "performances reproduced the organization that was rather than producing the organization that could be" (ibid, p. 748). This kind of behavior is echoed in Swidler's observation that, even when change is desired, "old orders are ... resilient, hiding their premises in the minutiae of daily life" (1986, p. 277). By regarding culture as a set of strategies of action that are drawn into use, even when they are not welcome, and also tools that can be put to use, future work might explore how routines' entanglement with culture can shed new light on routine persistence and change. 
In closing, the question of how an organization integrates another's routines and brings them to life is both important and under studied (Pentland and Feldman 2005, Rerup 2004, Winter and Szulanski 2002). Our attention to the process of routine integration and the way it is shaped by employees' use of an organization's culture informs our understanding of routine dynamics more broadly. Because routine integration can be seen as a specific flavor of the broader set of moves that include adoption or planned change of routines, our theory-building informs this broader conversation by offering a more nuanced explanation of embeddedness, suggesting a revised way to think about routines as truces, and illuminating how performing routines and performing culture are intimately connected. Overall, our analysis contributes to improved understanding of how routines interact with organizational contexts, entangling the dynamic understanding of routines with a more dynamic understanding of organizational life.

\section{References}

Alter, S. 2014. Theory of workarounds. Commun. Assoc. Inf. Syst. 34 1041-1066.

Ansari, S. M., P. C. Fiss, E. J. Zajac. 2010. Made to fit: How practices vary as they diffuse. Acad. Manage. Rev. 35(1) 67-92.

Ansari, S. S., J. Reinecke, A. Spaan. 2014. How are practices made to vary? Managing practice adaptation in a multinational corporation. Organ. Stud. 35(9) 1313-1341.

Argote, L., E. Darr. 2000. Repositories of knowledge in franchise organizations: Individual, structural and technological. G. Dosi, R. R. Nelson, S. G. Winter, eds. Nat. Dyn. Organ. Capab. Oxford University Press, 51-65.

Bertels, S., J. Peloza. 2008. Running Just to Stand Still? Managing CSR Reputation in an Era of Ratcheting Expectations. Corp. Reput. Rev. 11(1) 56-72.

Besharov, M. L. 2014. The relational ecology of identification: How organizational identification emerges when individuals hold divergent values. Acad. Manage. J. 57(5) 1485-1512.

Bruns, H. C. 2009. Leveraging functionality in safety routines: Examining the divergence of rules and performance. Hum. Relat. 62(9) 1399-1426. 
Cacciatori, E. 2012. Resolving conflict in problem-solving: Systems of artefacts in the development of new routines. J. Manag. Stud. 49(8) 1559-1585.

Canales, R. 2013. Weaving straw into gold: Managing organizational tensions between standardization and flexibility in microfinance. Organ. Sci. 25(1) 1-28.

Canato, A., D. Ravasi, N. Phillips. 2013. Coerced practice implementation in cases of low cultural fit: Cultural change and practice adaptation during the implementation of Six Sigma at 3M. Acad. Manage. J. 56(6) 1724-1753.

Charmaz, K. 2006. Constructing Grounded Theory: A Practical Guide Through Qualitative Analysis. Thousand Oaks, CA, SAGE Publications Inc.

D’Adderio, L. 2014. The replication dilemma unravelled: How organizations enact multiple goals in routinetTransfer. Organ. Sci. 25(5) 1325-1350.

Darr, E. D., L. Argote, D. Epple. 1995. The acquisition, transfer, and depreciation of knowledge in service organizations: Productivity in franchises. Manag. Sci. 41(11) 1750-1763.

David, R. J., D. Strang. 2006. When fashion is fleeting: Transitory collective beliefs and the dynamics of TQM consulting. Acad. Manage. J. 49(2) 215-233.

Edmondson, A. C., R. M. Bohmer, G. P. Pisano. 2001. Disrupted routines: Team learning and new technology implementation in hospitals. Adm. Sci. Q. 46(4) 685-716.

Feldman, M. S. 2000. Organizational routines as a source of continuous change. Organ. Sci. 11(6) 611629.

Feldman, M. S. 2003. A performative perspective on stability and change in organizational routines. Ind. Corp. Change 12(4) 727-752.

Feldman, M. S., B. T. Pentland. 2003. Reconceptualizing organizational routines as a source of flexibility and change. Adm. Sci. Q. 48(1) 94-118.

Friesl, M., J. Larty. 2013. Replication of routines in organizations: Existing Literature and new perspectives. Int. J. Manag. Rev. 15(1) 106-122. 
Gersick, C. J., J. R. Hackman. 1990. Habitual routines in task-performing groups. Organ. Behav. Hum. Decis. Process. 47(1) 65-97.

Gondo, M. B., J. M. Amis. 2013. Variations in practice adoption: The roles of conscious reflection and discourse. Acad. Manage. Rev. 38(2) 229-247.

Harrison, S. H., K. G. Corley. 2011. Clean climbing, carabiners, and cultural cultivation: Developing an open-systems perspective of culture. Organ. Sci. 22(2) 391-412.

Hatch, M. J., M. Schultz. 2002. The dynamics of organizational identity. Hum. Relat. 55(8) 989-1018.

Howard-Grenville, J. A. 2005. The persistence of flexible organizational routines: The role of agency and organizational context. Organ. Sci. 16(6) 618-636.

Howard-Grenville, J. A., K. Golden-Biddle, J. Irwin, J. Mao. 2011. Liminality as cultural process for cultural change. Organ. Sci. 22(2) 522-539.

Hynes, T., P. Prasad. 1997. Patterns of "mock bureaucracy" in mining disasters: An analysis of the Westray coal mine explosion. J. Manag. Stud. 34(4) 601-623.

Kellogg, K. C. 2011. Hot lights and cold steel: Cultural and political toolkits for practice change in surgery. Organ. Sci. 22(2) 482-502.

Knott, A. M. 2003. The organizational routines factor market paradox. Strateg. Manag. J. 24(10) 929943.

Kostova, T. 1999. Transnational transfer of strategic organizational practices: A contextual perspective. Acad. Manage. Rev. 24(2) 308-324.

Kostova, T., K. Roth. 2002. Adoption of an organizational practice by subsidiaries of multinational corporations: Institutional and relational effects. Acad. Manage. J. 45(1) 215-233.

Locke, K. 2001. Grounded theory in management research. SAGE Publications Inc.

Lozeau, D., A. Langley, J.-L. Denis. 2002. The corruption of managerial techniques by organizations. Hum. Relat. 55(5) 537-564.

Maritan, C. A., T. H. Brush. 2003. Heterogeneity and transferring practices: Implementing flow manufacturing in multiple plants. Strateg. Manag. J. 24(10) 945-959. 
Narduzzo, A., E. Rocco, M. Warglien. 2000. Talking about routines in the field: The emergence of organizational capabilities in a new cellular phone network company. G. Dosi, R. R. Nelson, S. G. Winter, eds. Nat. Dyn. Organ. Capab. New York, Oxford University Press.

Nelson, R. R., S. G. Winter. 1982. An Evolutionary Theory of Economic Change. Cambridge, MA, Belknap Press.

Orlikowski, W. J., S. V. Scott. 2008. Sociomateriality: Challenging the separation of technology, work and organization. Acad. Manag. Ann. 2(1) 433-474.

Ouchi, W. G. 1980. Markets, bureaucracies, and clans. Adm. Sci. Q. 129-141.

Pentland, B. T., M. S. Feldman. 2005. Organizational routines as a unit of analysis. Ind. Corp. Change 14(5) 793-815.

Pentland, B. T., H. H. Rueter. 1994. Organizational routines as grammars of sction. Adm. Sci. Q. 39(3) $484-510$.

Rerup, C. 2004. Imperfection, transfer failure, and the replication of knowledge: An interview with Gabriel Szulanski. J. Manag. Inq. 13(2) 141-150.

Rerup, C., M. S. Feldman. 2011. Routines as a source of change in organizational schemata: The role of trial-and-error learning. Acad. Manage. J. 54(3) 577-610.

Reynaud, B. 2005. The void at the heart of rules: Routines in the context of rule-following. The case of the Paris Metro Workshop. Ind. Corp. Change 14(5) 847-871.

Rindova, V., E. Dalpiaz, D. Ravasi. 2011. A cultural quest: A study of organizational use of new cultural resources in strategy formation. Organ. Sci. 22(2) 413-431.

Sewell, W. H. 1992. A theory of structure: Duality, agency, and transformation. Am. J. Sociol. 89 1-29.

Swidler, A. 1986. Culture in action: Symbols and strategies. Am. Sociol. Rev. 273-286.

Swidler, A. 2001. Talk of love: How culture matters. University of Chicago Press.

Szulanski, G. 2000. Appropriability and the challenge of scope. G. Dosi, R. R. Nelson, S. G. Winter, eds. Nat. Dyn. Organ. Capab. Oxford, Oxford University Press, 69-98.

Trice, H. M., J. M. Beyer. 1993. The Cultures of Work Organizations. Prentice-Hall, Inc. 
Tucker, A. L., A. C. Edmondson. 2003. Why hospitals don’t learn from failures: Organizational and psychological dynamics that inhibit system change. Calif. Manage. Rev. 45(2) 55-72.

Turner, S. F., M. J. Fern. 2012. Examining the stability and variability of routine performances: The effects of experience and context change. J. Manag. Stud. 49(8) 1407-1434.

Turner, S. F., V. Rindova. 2012. A balancing act: How organizations pursue consistency in routine functioning in the face of ongoing change. Organ. Sci. 23(1) 24-46.

Tyre, M. J., W. J. Orlikowski. 1994. Windows of Opportunity: Temporal Patterns of Technological Adaptation in Organizations. Organ. Sci. 5(1) 98-118.

Van Maanen, J. 1979. The fact of fiction in organizational ethnography. Adm. Sci. Q. 539-550.

Wang, T., P. Bansal. 2012. Social responsibility in new ventures: Profiting from a long-term orientation. Strateg. Manag. J. 33(10) 1135-1153.

Weber, K., M. T. Dacin. 2011. The cultural construction of organizational life: Introduction to the special issue. Organ. Sci. 22(2) 287-298.

Westphal, J. D., R. Gulati, S. M. Shortell. 1997. Customization or conformity? An institutional and network perspective on the content and consequences of TQM adoption. Adm. Sci. Q. 42(2).

Winter, S. G., G. Szulanski. 2001. Replication as strategy. Organ. Sci. 12(6) 730-743.

Winter, S., G. Szulanski. 2002. Replication of organizational routines: Conceptualizing the exploitation of knowledge assets. C. W. Choo, N. Bontis, eds. Strateg. Manag. Intellect. Cap. Organ. Knowl. Oxford University Press, 207-221.

Zbaracki, M. J., M. Bergen. 2010. When truces collapse: A longitudinal study of price-adjustment routines. Organ. Sci. 21(5) 955-972. 
Table 1: Description of Data

\begin{tabular}{l} 
Data Types (Dates) \\
\hline Primary Data \\
Interviews \\
82 semi-structured interviews, lasting \\
between 45 minutes and two hours. \\
(Conducted between 08/2009 and \\
07/2015.)
\end{tabular}

4 focus groups, lasting between 2 hours and 6 hours with onsite EH\&S staff and corporate sustainability personnel.

(Conducted between 04/28/10 and 12/17/12).

2-day knowledge forum attended by industry, regulators, prosecutors, NGOs and the public (closed door session with industry, regulators and prosecutors on day 2)

\section{Observation}

Site visits to Northsite, (conducted between 04/28/10 and 06/20/12)

Site visits to head office, lasting between 1 and 3 days (conducted between 08/2009 and 01/2014)

EH\&S training session on Operational Excellence (06/19/12)

\section{Check-in Calls}

15 quarterly check-in calls with 2 key informants (head of EH\&S at Northsite and Manager of Sustainability at head office; conducted between 12/2009 and 04/2015)

\section{Secondary Data}

Oilco's Sustainability and Annual

Reports (2003-2013)

Oilco internal newsletters (2009-2014)

Amount

Use in Analysis

2183 pages of text (verbatim transcriptions from audiotape)

168 pages of text (verbatim transcriptions from audiotape)

2 days of discussion; 6 pages of notes; summary document; exit survey of participants including written comments

3 visits lasting between 2 and 4 days

8 pages of field notes

9 visits lasting between 1 and 2 days

16 pages of field notes

Attended the training session and the evening social event

26 pages of notes

17 reports

6 newsletters
Insight into timeline of events, efforts to drive operational excellence and enactment of operational compliance routine

Insight into timeline of events, efforts to drive operational excellence and enactment of operational compliance routine

Insight into industry trends in trying to implement operational excellence and operational compliance

Participant observation yielding insight into enactment of operational compliance routine

Participant observation yielding insight into efforts to drive operational compliance

Participant observation yielding insight into efforts to drive operational compliance and the outcomes of those efforts

Insight into efforts to drive operational compliance and the outcomes of those efforts

Construct timeline.

Statements made by Senior Leaders about Operational Compliance and the Operational Compliance routine. 


\section{Figure 1: Espoused Operational Compliance Routine at Oilco}

\begin{tabular}{|c|c|c|}
\hline Stage & Step \# & Espoused Routine \\
\hline $\begin{array}{l}\text { Building and } \\
\text { maintaining the } \\
\text { RegCompliance } \\
\text { Tool }\end{array}$ & 1 & Reg Team identifies and adds relevant compliance obligations to the RegCompliance Tool. \\
\hline \multirow{3}{*}{$\begin{array}{l}\text { Ensuring } \\
\text { compliance in the } \\
\text { design and } \\
\text { construction of } \\
\text { new assets }\end{array}$} & 2 & $\begin{array}{l}\text { Design/Build uses the RegCompliance Tool to identify the obligations that could be relevant } \\
\text { to the design of a new asset. }\end{array}$ \\
\hline & 3 & $\begin{array}{l}\text { Design/Build tracks, completes and documents the compliance obligations related to the } \\
\text { construction of the asset using the RegCompliance Tool. }\end{array}$ \\
\hline & 4 & $\begin{array}{l}\text { Design /Build updates the RegCompliance Tool during the design and construction of the } \\
\text { asset to track and document compliance obligations related to the future operation of the asset. }\end{array}$ \\
\hline $\begin{array}{l}\text { Ensuring } \\
\text { compliance in the } \\
\text { handover of new } \\
\text { assets to } \\
\text { Operations } \\
\end{array}$ & 5 & $\begin{array}{l}\text { At the handover of the asset, the Design/Build group coordinates with the Operations group to } \\
\text { transfer the compliance knowledge and obligations of the newly built asset and to ensure that } \\
\text { the compliance obligations are fully outlined and tasked in the RegCompliance Tool. }\end{array}$ \\
\hline \multirow{4}{*}{$\begin{array}{l}\text { Ensuring } \\
\text { compliance in the } \\
\text { operation of } \\
\text { assets }\end{array}$} & 6 & $\begin{array}{l}\text { With support from Operations, the RegTeam translates compliance obligations into a well- } \\
\text { specified set of ongoing operational tasks in the RegCompliance Tool and ensures all tasks in } \\
\text { the RegCompliance Tool are assigned to specific employees. }\end{array}$ \\
\hline & 7 & $\begin{array}{l}\text { Employees complete the tasks and document their completion in the RegCompliance Tool } \\
\text { (and where required, append supporting documentation). }\end{array}$ \\
\hline & 8 & $\begin{array}{l}\text { Supervisors track the status of completion of tasks using the RegCompliance dashboard. } \\
\text { When tasks are near due but remain uncompleted, supervisors follow up with employees. }\end{array}$ \\
\hline & 9 & $\begin{array}{l}\text { Senior managers are alerted to overdue tasks through the RegCompliance dashboard and } \\
\text { follow-up to determine why a task is overdue, ensure that it gets completed and determine } \\
\text { why it was not completed. }\end{array}$ \\
\hline $\begin{array}{l}\text { Updating the } \\
\text { RegCompliance } \\
\text { Tool }\end{array}$ & 10 & $\begin{array}{l}\text { Reg Team identifies new regulations or changes in regulation and updates the tasks in the } \\
\text { RegCompliance Tool. } \\
\text { On an ongoing basis, Operations managers update the RegCompliance Tool to include } \\
\text { changes in tasks or new tasks stemming from changes in operations. (Design/Build can then } \\
\text { use this updated understanding of the compliance requirements to guide the design of future } \\
\text { assets). }\end{array}$ \\
\hline $\begin{array}{l}\text { Verifying } \\
\text { adherence to the } \\
\text { procedures }\end{array}$ & 11 & An audit team conducts random checks that all of these elements are actually being enacted. \\
\hline
\end{tabular}




\section{Figure 2: Enacted Operational Compliance Routine at Oilco}

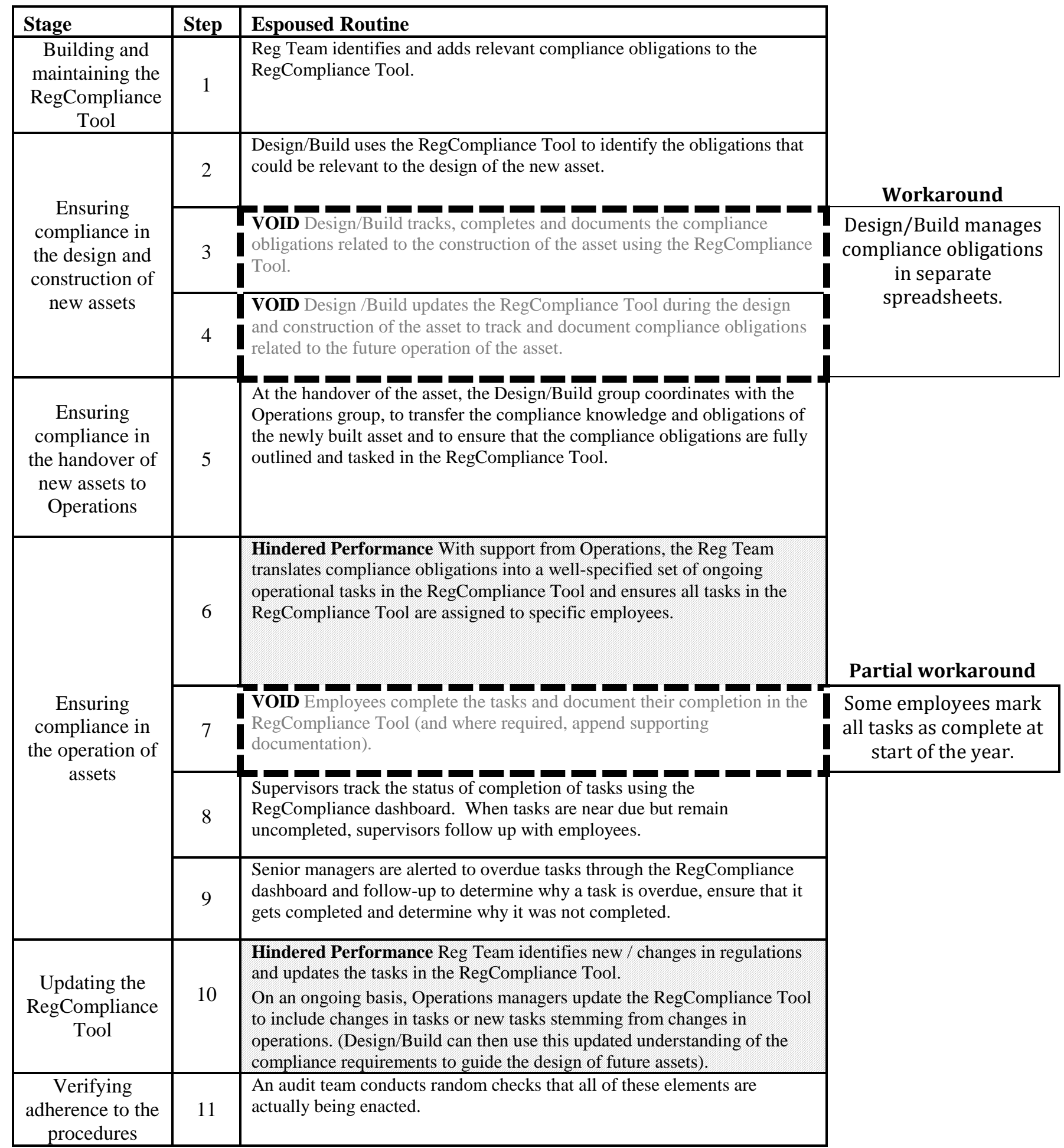

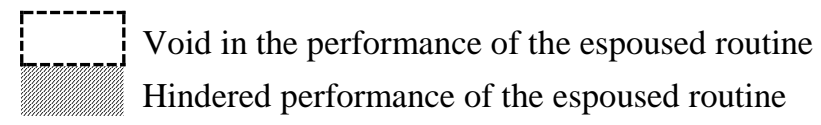


Figure 3: Cultural Shielding and Cultural Shoring

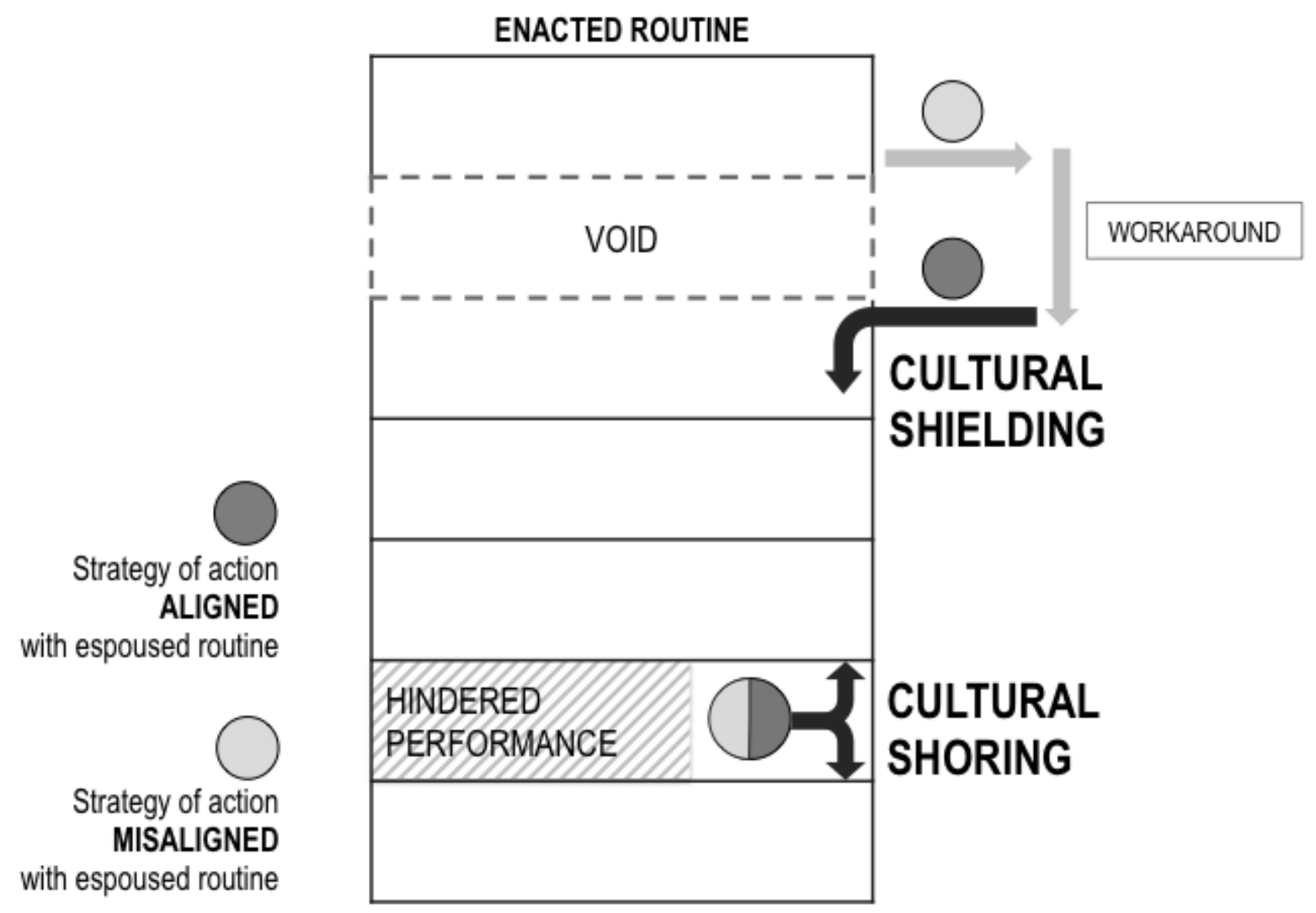

